\title{
AN UNIQUE EDGE PRESERVING NOISE FILTERING TECHNIQUE FOR IMPULSE NOISE REMOVAL
}

\author{
Kartik Sau $^{1}$, Amitabha Chanda ${ }^{2}$, Pabitra Karmakar ${ }^{3}$ \\ ${ }^{1}$ Department of Computer Science \& Engineering, Budge Budge Institute of \\ Technology, Nischintapur. Kolkata 7000137, WBUT, India, \\ kartik_sau2001@yahoo.co.in \\ ${ }^{2}$ Guest faculty, UCSTA, University of Calcutta, West Bengal, India. \\ amitabha39@yahoo.co.in \\ ${ }^{3}$ Department of Computer Science \& Engineerin, Institute of Engineering and \\ Management, WBUT, Salt Lake, Sec -V, Kolkata - 700091, India. \\ pab_compeyahoo.co.in
}

\begin{abstract}
Image de-noising is the technique to reduce noises from corrupted images. The aim of the image denoising is to improve the contrast of the image or perception of information in images for human viewers or to provide better output for other automated image processing techniques. This paper presents a new approach for color image de-noising with Fuzzy Filtering techniques using centroid method for defuzzification. It preserves any type of edges (including tiny edges) in any direction. The experimental result shows the effectiveness of the proposed method.
\end{abstract}

\section{Keywords}

Impulse noise; Median filter; Color image de-noising; Defuzzification; Edge Preservation;

\section{INTRODUCTION}

Color provides a significant portion of visual information to human beings and enhances their ability of object detection. In the RGB color model, the three primaries are Red, Green, and Blue. They can be combined, two at a time to create the secondary hues. Magenta is $(\mathrm{R}+\mathrm{B})$, cyan is $(B+G)$, and yellow is $(R+G)$. There are two reasons for using the red, green, and blue colors as primaries: (1) the cones in the eye are very sensitive to these colors and (2) adding red, green, and blue can produce many colors although not all colors. For various reasons digital images are often contaminated with noise at the time of acquisition or transmission. The noise introduces itself into an image by replacing some of the pixels of the original image by new pixels having luminance values near or equal to the minimum or maximum of the allowable dynamic luminance range. Pre-processing of an image is conducted with a view to adjusting the image for further classification and segmentation. In the process, however, image features should not be destroyed. This is a difficult task in any image processing system. For this purpose various types of filters are used. Among those median filter is an important class of filters. In the present paper we shall discuss some of the median filters. 
Signal \& Image Processing : An International Journal (SIPIJ) Vol.2, No.3, September 2011

\subsection{Different median filters:}

Some important median filters are discussed below in short.

The standard median filter $[28,24,8,17,11]$ : In this filter luminance values in a window are arranged in an order and the median value is selected. This filter reduces noise reasonably well, but in the process some information is also lost at low noise densities.

The weighted median filter $[30,19,11,10]$ and the centre-weighted median filter $[16,13,25,6,11]$ have been proposed to avoid the inherent drawbacks of the standard median filter by controlling the trade off between the noise suppression and detail preservation.

The switching median filter [31,11] is a type of median filter with an impulse detector. It is so designed that if the centre pixel is identified by the detector as a corrupted pixel, then it is replaced with the output of the median filter, otherwise, it is left unchanged. The tri state median filter [7] and the multi-state median filter (MSMF) [8] are two modification of switching median filter.

Two other types of switching median filters worth mentioning are progressive switching median filter (PSMF) [29] and Signal-dependent rank-ordered mean filter (SDROMF) [1,2].

The progressive switching median filter (PSMF) [29] is a derivative of the basic switching median filter. In this filtering approach, detection and removal of impulse noise are iteratively done in two separate stages. Despite its improved filtering performance it has a very high computational complexity due to its iterative nature. Signal-dependent rank-ordered mean filter (SDROMF) [1,2] uses rank-ordered mean filter.

Adaptive centre weighted median (ACWM) [19,11] filter avoids the drawbacks of the CWM filters and switching median filter. Input data will be clustered by scalar quantization (SQ) method, this results in fixed threshold for all of images.

Fuzzy-Median filters of different types have gained lot of importance in image processing. Some such filters $[3,18,27,5,22,15]$ are worth mentioning.

\section{PROPOSED METHOD FOR DE-NOISING}

\subsection{Phase I}

Any given digital RGB color image can be represented by a two dimensional array of size $\mathrm{M} \times \mathrm{N}$ for each Red, Green and Blue primaries. When we are capturing or transmitting the images, then there will be some noises due to improper opening and closing of the shutter, atmospheric turbulence, misfocus of lens, relative motion between camera and objects [12]. For removing the noise from the image we can pursue the following steps:

Step 1: Let the input and output images of median filter are $\mathrm{X}(i, j) \& \mathrm{y}_{1}(i, j)$ respectively. The median filter uniformly replaces the central pixel of a window (W) by the median of the pixels bounded by predefined window $(\mathrm{W})$ size $\mathrm{w} \times \mathrm{w}$. The output of the median filter $[26,10,32]$ is given by

$$
\begin{aligned}
& y_{l}(i, j)=\operatorname{median}\{\mathrm{X}(i-s ; j-t):(s, t) \varepsilon \mathrm{W}\} \\
& \text { and } W=\{(s, t):-n \leq s, t \leq n\}
\end{aligned}
$$


Signal \& Image Processing : An International Journal (SIPIJ) Vol.2, No.3, September 2011

Here we consider $n=1$

Step 2: The pixel values of the neighborhood pixels of $(i, j)$ of original image are sorted in some specific order.

Step 3: The Fuzzy membership [14,22,20,17] value is assigned for each pixel in a window of w $\times$ w size using some suitable membership functions. The membership function used here is given below.

(i) A triangular shaped membership function is used.

(ii) The highest and lowest gray values get the membership value zero.

(iii) Assign the membership value 1 to the mean value of the gray level of the window of size $\mathrm{W} \times \mathrm{W}$.

The triangular membership function [14,20,17], also called bell-shaped function with straight lines, can be defined as follows:

$$
\begin{aligned}
\mu(x ; \alpha, \beta, \gamma) & =0 & & \text { if } x \leq \alpha \\
& =(x-\alpha) /(\beta-\alpha+1) & & \text { if } \alpha<x \leq \beta \\
& =(\alpha-x) /(\beta-\alpha+1) & & \text { if } \beta<x \leq \gamma
\end{aligned}
$$

One typical plot of the triangular membership is given in the following figure.

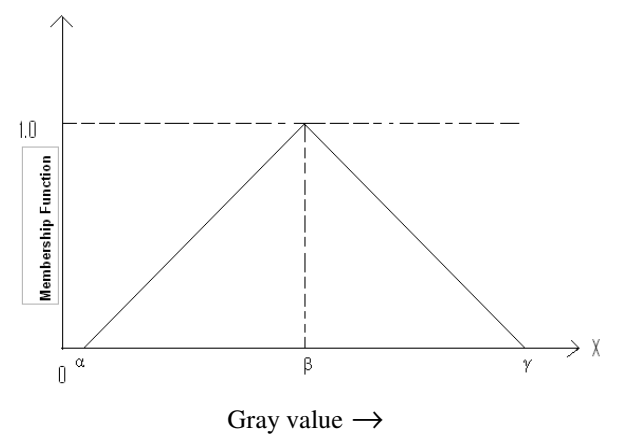

Figure 1: Triangular membership function

Step 4: Now de-fuzzyfy [14,20,21,32] the membership value using the Centroid method by the following formula, and select the output for that window. Let it be $y_{2}(i, j)$ at the point $(i, j)$ in the window of size $\mathrm{w} \times \mathrm{w}$

$$
y_{2}(i, j)=\frac{\sum_{x} \underset{x}{x \mu(i, j)}}{\sum_{x} \underset{x}{\mu}(i, j)}
$$

\subsection{Phase II}

If we apply the phase I on the noisy images, noise would be removed. But the problem is, though the noises are represented as 0 and 255, so all 0 and 255 will also be removed; even of those were not noises. For preserving the actual data we pursues the following steps 
Signal \& Image Processing : An International Journal (SIPIJ) Vol.2, No.3, September 2011

Step 1: For the noisy pixel at the point $(i, j)$, we compute $p(i, j)$ and $q(i, j)$ by the following formulas [21]:

$p(i, j)=|f(i, j)-\operatorname{median}\{\operatorname{Lf}(i, j)\}|$.

Here $\mathrm{L}(\mathrm{f}(i, j))$ is the 8-neighborhood of point $(\mathrm{i}, \mathrm{j})$.

$q(i, j)=\frac{\left|f(i, j)-f c_{1}(i, j)\right|+\left|f(i, j)-f c_{2}(i, j)\right|}{2}$

Here $f c_{1}(i, j), f c_{2}(i, j)$ are the closest values of $\mathrm{f}(i, j)$ in the filter window of size $\mathrm{w} \times \mathrm{w}$.

Then rearrange $\mathrm{p}(i, j)$ and $\mathrm{q}(i, j)$ in ascending order for all $\mathrm{i}, \mathrm{j}=0,1,2$.

Step2: Compute $w(i, j)=\mathrm{F}(\mathrm{p}(i, j), \mathrm{q}(i, j))$ such that

$$
w(i, j)=1-\frac{p(i, j)+k_{1}}{p(i, j)+q(i, j)+k_{2}}
$$

Here $\mathrm{k}_{1}$ and $\mathrm{k}_{2}$ are real quantity, which depends on the quality of the input images. Select the maximum $\mathrm{w}(i, j)$.

Step3: $\quad$ If $\quad \mathrm{y}_{1}(i, j) \neq \mathrm{y}_{2}(i, j)$

$$
\begin{aligned}
& \text { then } \quad y_{3}(i, j)=w(i, j) y_{1}(i, j)+\left(1-w(i, j) y_{2}(i, j)\right) \\
& \text { Else } \quad \mathrm{y}_{3}(i, j)=\mathrm{y}_{1}(i, j)
\end{aligned}
$$

Step 4: Continue this process for all the pixels which are noisy.

The computational procedure is illustrated below.

Example: Consider a color image of size $3 \times 3$, as follows,

Table 1: color image with size $3 \times 3$

\begin{tabular}{|c|c|c|}
\hline 163 & 193 & 151 \\
\hline 179 & 0 & 138 \\
\hline 192 & 172 & 127 \\
\hline
\end{tabular}

Red

\begin{tabular}{|c|c|c|}
\hline 83 & 113 & 71 \\
\hline 99 & 0 & 58 \\
\hline 112 & 92 & 47 \\
\hline
\end{tabular}

Green

\begin{tabular}{|c|c|c|}
\hline 55 & 81 & 39 \\
\hline 68 & 0 & 29 \\
\hline 85 & 63 & 21 \\
\hline
\end{tabular}

Blue 
Signal \& Image Processing : An International Journal (SIPIJ) Vol.2, No.3, September 2011 For the Green component, we calculate membership values as follows

Original value: 0 Mean value: 75 Median value $\mathrm{y}_{1}(i,, j): 83$

Table 2 : Membership values for pixels

\begin{tabular}{|c|c|c|c|c|c|c|c|c|c|}
\hline $\begin{array}{c}\text { Sorted } \\
\text { order }\end{array}$ & 0 & 47 & 58 & 71 & 83 & 92 & 99 & 112 & 113 \\
\hline $\begin{array}{c}\text { Member } \\
\text { ship } \\
\text { value }\end{array}$ & 0.00 & 0.26 & 0.55 & 0.89 & 0.79 & 0.55 & 0.37 & 0.26 & 0.00 \\
\hline
\end{tabular}

According to Table 2 the graph is as follows -

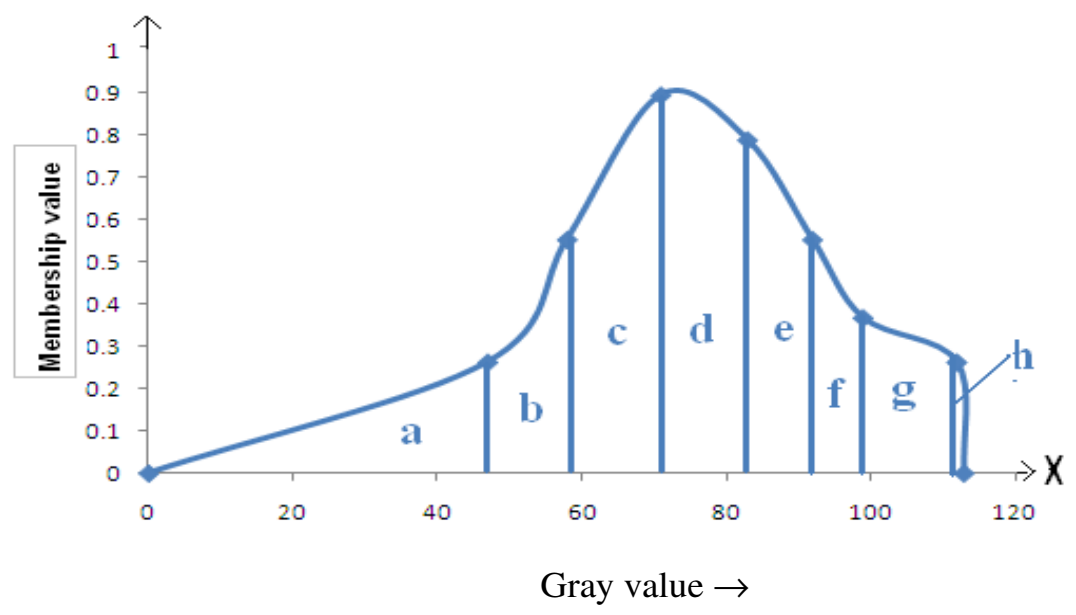

Figure 2

Now we calculate $\mathrm{y}_{2}(i, j)$ using centroid method

Table 3

\begin{tabular}{|c|c|c|}
\hline Sector & Area of the sector & Centroid of the sector \\
\hline $\mathrm{a}$ & 6.184211 & 23 \\
\hline $\mathrm{b}$ & 4.486842 & 52 \\
\hline $\mathrm{c}$ & 9.407894 & 64 \\
\hline $\mathrm{d}$ & 10.105263 & 77 \\
\hline $\mathrm{e}$ & 6.039474 & 87 \\
\hline $\mathrm{f}$ & 3.223684 & 95 \\
\hline $\mathrm{g}$ & 2.565789 & 105 \\
\hline $\mathrm{h}$ & 0.013158 & 112 \\
\hline
\end{tabular}


Signal \& Image Processing : An International Journal (SIPIJ) Vol.2, No.3, September 2011

So, the calculated value for $\sum_{x} x \underset{x}{\mu}(i, j)=2858.328857$

And the calculated value for $\sum_{x} \underset{x}{\mu}(i, j)=42.02631$

Therefore, $y_{2}(i, j)=68$ [Selected value in phase I ]

Rearranged $p(i, j)$ and $q(i, j)$ as follows

Table-4: Different values of $\mathrm{p}, \mathrm{q}$ and $\mathrm{w}$.

\begin{tabular}{|c|c|c|}
\hline $\mathbf{p}(\boldsymbol{i}, \boldsymbol{j})$ & $\mathbf{q}(\boldsymbol{i}, \boldsymbol{j})$ & $\mathbf{w}(\boldsymbol{i}, \boldsymbol{j})$ \\
\hline 0 & 7 & $\mathbf{0 . 9 5 6 5 2 2}$ \\
\hline 9 & 7.5 & 0.207792 \\
\hline 12 & 8 & 0.509804 \\
\hline 16 & 10 & 0.388889 \\
\hline 25 & 10.5 & 0.388278 \\
\hline 29 & 12 & 0.328947 \\
\hline 30 & 12.5 & 0.202703 \\
\hline 36 & 17.5 & 0.47222 \\
\hline 83 & 52.5 & 0.330275 \\
\hline
\end{tabular}

Therefore $\mathrm{y}_{3}(i, j)=82$

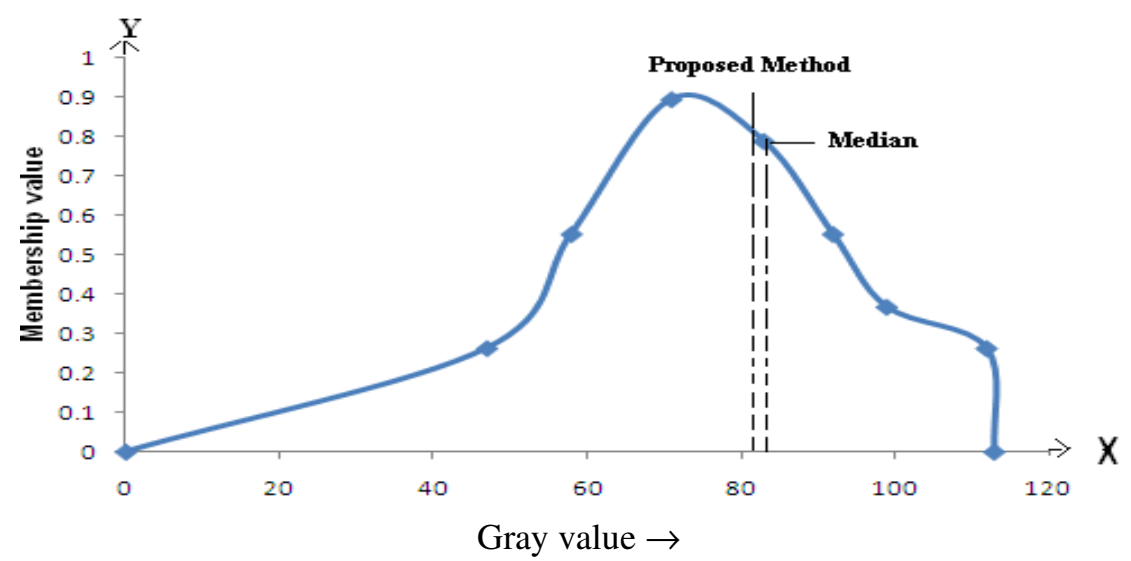

Figure 3

The figure 3 shows the membership function for the pixel values of Green component of RGB image. And also indicate the selected value in the proposed method of Green component.

Now, for the Red component of RGB image, the selected values are as follows

Original value: 0

Mean value: 146

Median value $\mathrm{y}_{1}(i, j): 163$ 
$y_{2}(i, j)=108[$ Selected value in phase I]

And $\mathrm{y}_{3}(i, j)=160[$ in Phase II]

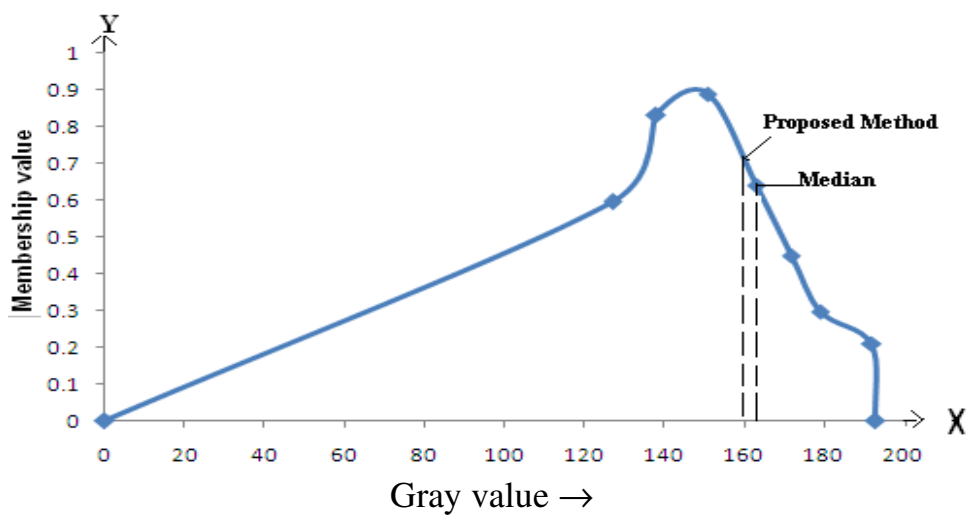

Figure 4 : Membership function for Red component

The Figure 4 shows the membership function for the pixel values of Red component of RGB image. And also indicate the selected value in proposed method for RED component.

Similarly, for the Blue component of RGB image, the selected values are as follows

Original value: 0

Mean value: 49

Median value $\mathrm{y}_{1}(i, j): 55$

$y_{2}(i, j)=47[$ Selected value in phase I]

and $\mathrm{y}_{3}(\mathrm{i}, \mathrm{j})=54$

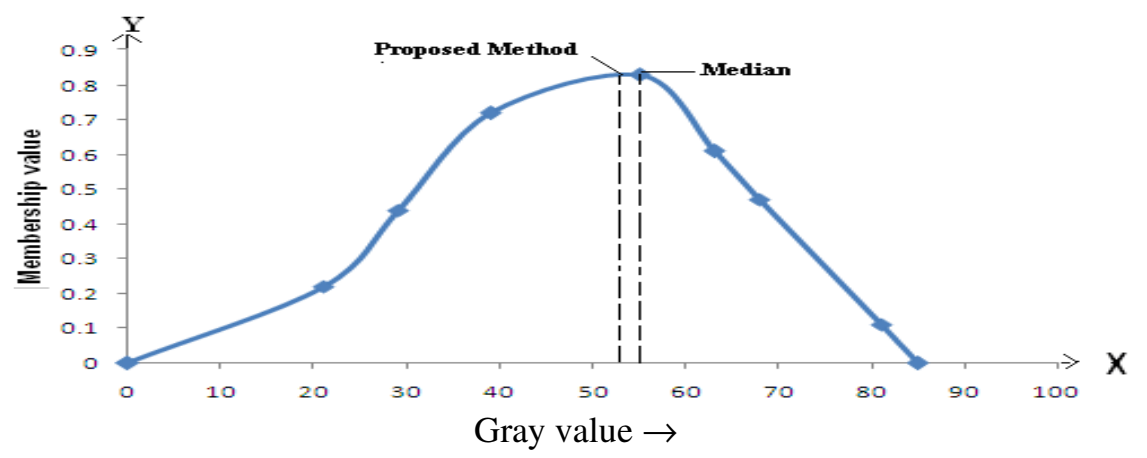

Figure 5: Membership function for Blue component

The Figure 5 shows the membership function for the pixel values of Blue components of RGB image. And also indicate the selected value in proposed method. 
Signal \& Image Processing : An International Journal (SIPIJ) Vol.2, No.3, September 2011

\section{FLOW CHART}

The flow chart of the proposed method is shown below.

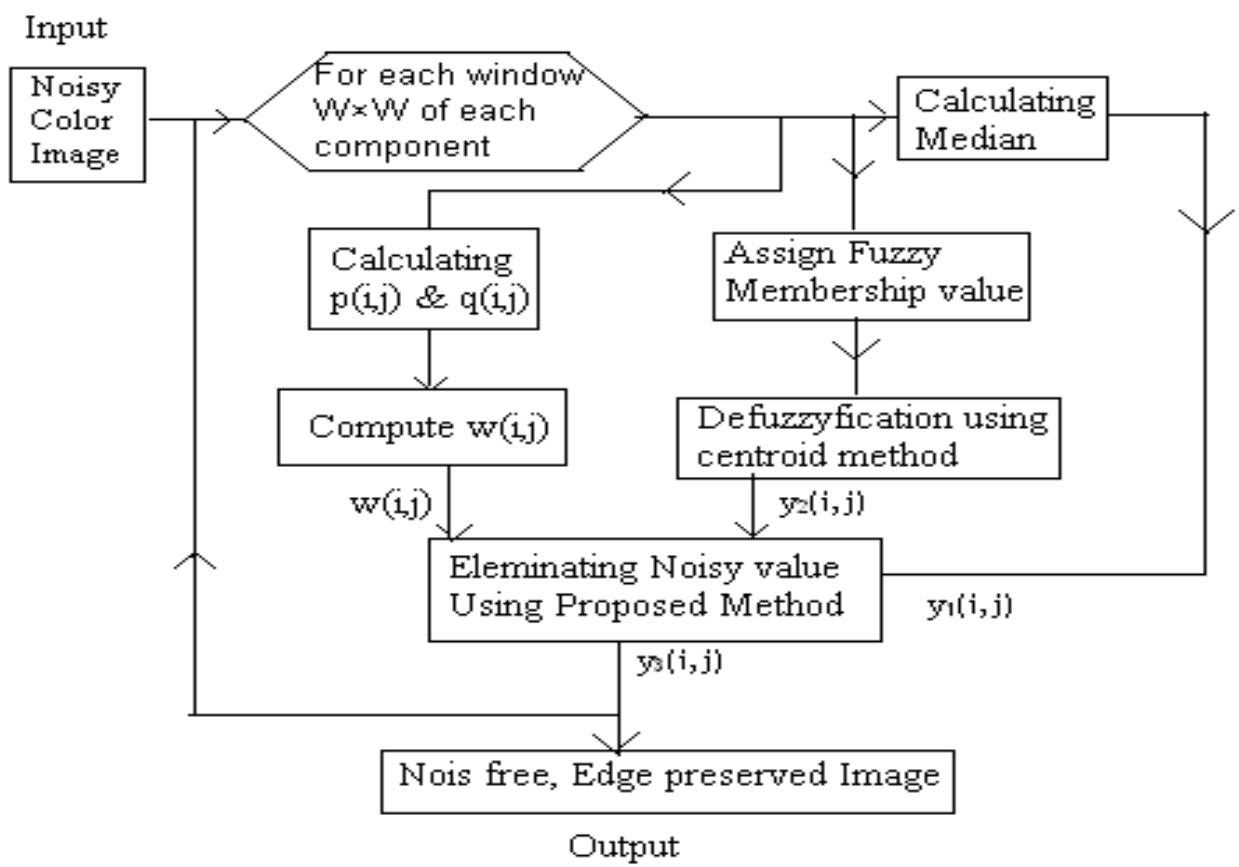

Figure 6

\section{EXPERIMENTAL RESULT}

The effectiveness of the proposed method is shown experimentally. It eliminates the fixed value impulse noise. And it is tested for different images in different sizes. The peak signal-tonoise ratio (PSNR) $[19,22,23,27,29,30]$ value gives the performance of restoration quantitatively, which is defined as

$$
P S N R=10 \log _{10}\left(\frac{\sum_{k} 255^{2}}{\sum_{k}(d(k)-y(k))^{2}}\right)
$$

Where 255 is the peak pixel value of the image, $\mathrm{d}(k)$ represents the value of the desired output, and $\mathrm{y}(k)$ represents the value of the physical output.

The experimental results were compared with median-filter (MED). 
Signal \& Image Processing : An International Journal (SIPIJ) Vol.2, No.3, September 2011

\subsection{Original Images}

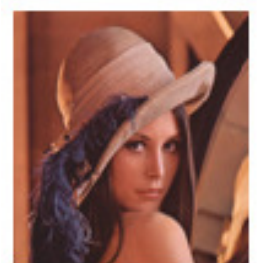

lena

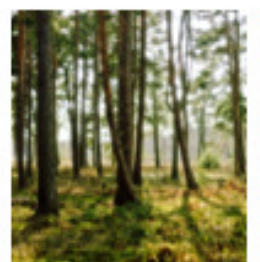

forest

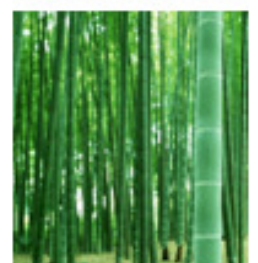

bamboo

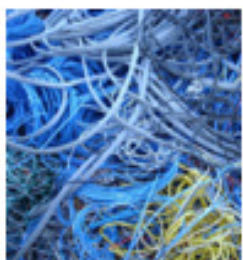

wires

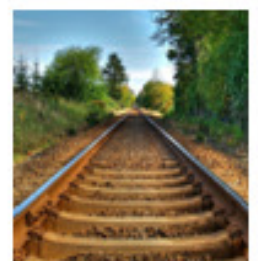

track

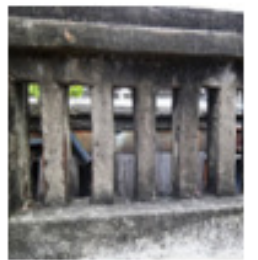

s1

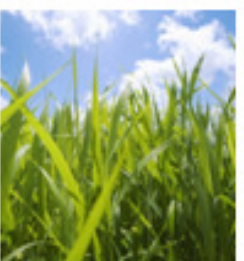

grass

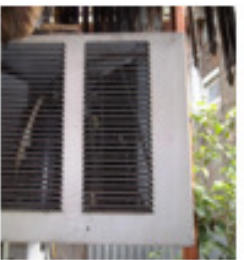

s2

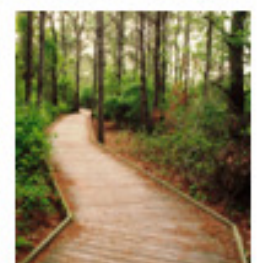

road

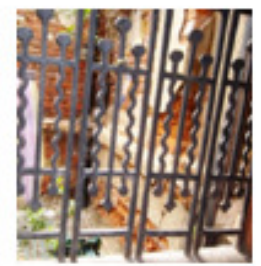

s3

\subsection{Noisy Images}

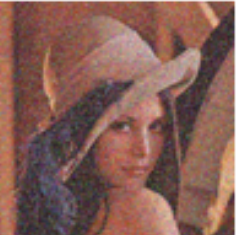

n_lena

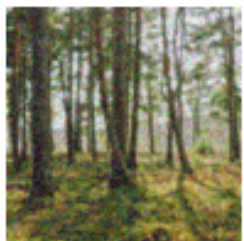

n_forest

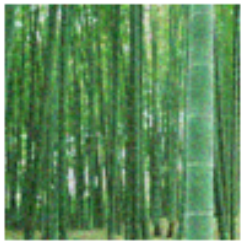

n_bamboo

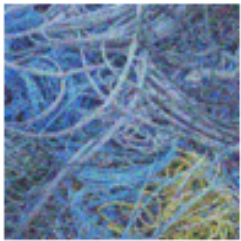

n_wires

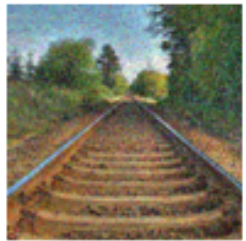

n_track

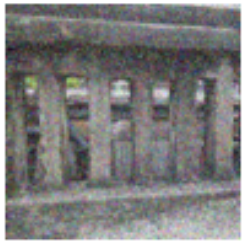

n_s1

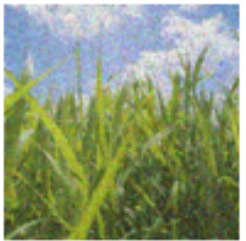

n_grass

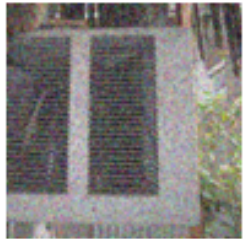

$\mathrm{n}_{-} \mathrm{s} 2$

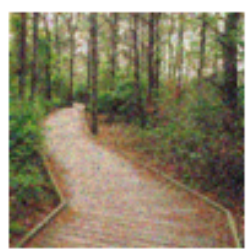

n_road

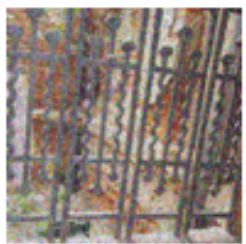

n_s3 
Signal \& Image Processing : An International Journal (SIPIJ) Vol.2, No.3, September 2011

\subsection{Median Filter Output}
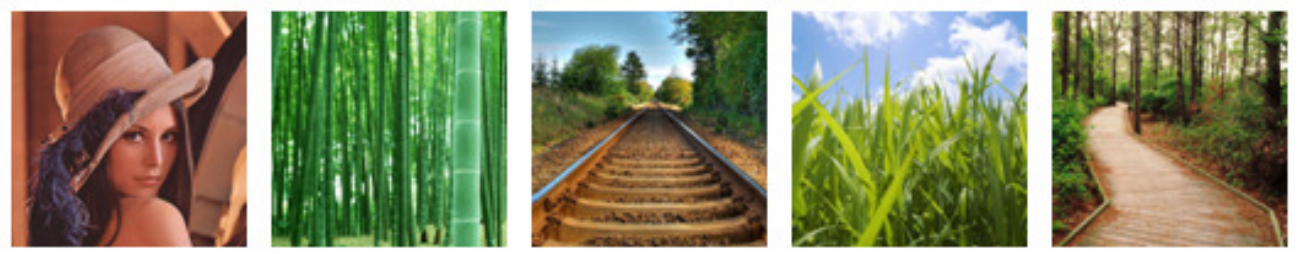

m_lena

m_bamboo

m_track

m_grass

m_road

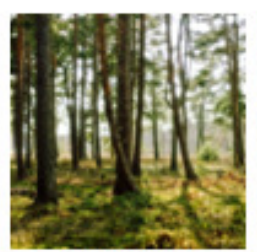

$\mathrm{m}_{-}$forest

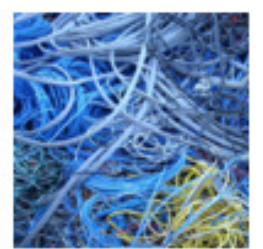

m_wires

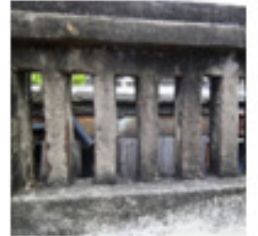

$\mathrm{m}_{-} \mathrm{s} 1$

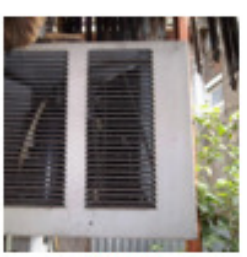

$\mathrm{m}_{-} \mathrm{s} 2$

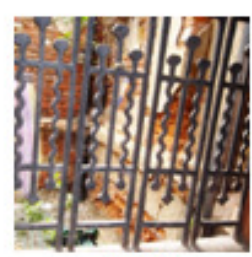

$\mathrm{m}_{-} \mathrm{s} 3$

\subsection{Proposed Filter Output}

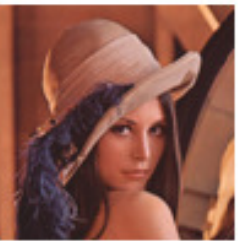

p_lena

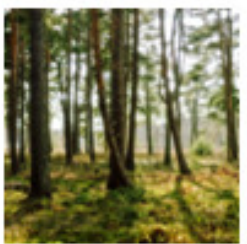

p_forest

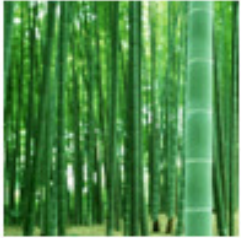

p_bamboo

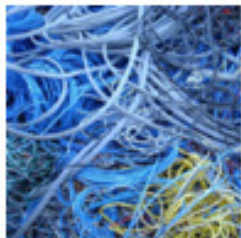

p_wires

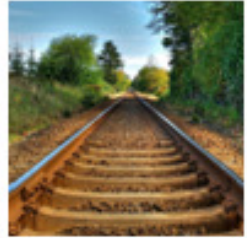

p_track

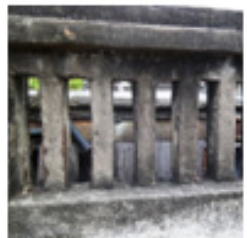

p_s1

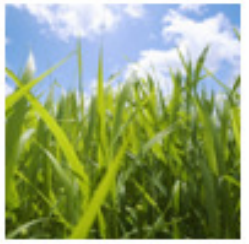

p_grass

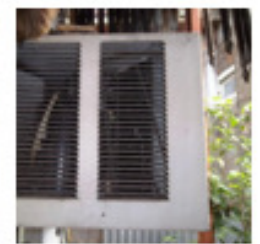

p_s2

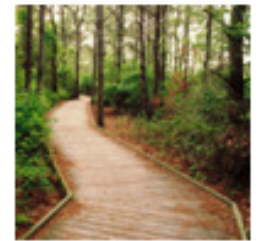

p_road

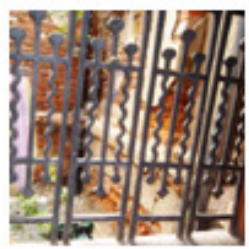

p_s3 
Signal \& Image Processing : An International Journal (SIPIJ) Vol.2, No.3, September 2011

Table 5: PSNR Comparison Table

\begin{tabular}{|c|c|c|}
\hline Image name & PSNR for Median Filter & PSNR Proposed filter \\
\hline lena & 27.583501 & 27.588477 \\
\hline bamboo & 25.972569 & 25.980521 \\
\hline track & 25.941161 & 25.949895 \\
\hline grass & 24.008344 & 24.012961 \\
\hline road & 25.584527 & 25.599688 \\
\hline forest & 25.729469 & 25.743479 \\
\hline wires & 23.657962 & 23.666070 \\
\hline s1 & 25.216643 & 25.2242 \\
\hline s2 & 24.469417 & 24.473686 \\
\hline s3 & 24.610376 & 24.618010 \\
\hline
\end{tabular}

Table 6: Edge Count Comparison Table

\begin{tabular}{|c|c|c|c|}
\hline Image name & Original Image & $\begin{array}{c}\text { Median Filter } \\
\text { Output }\end{array}$ & $\begin{array}{c}\text { Proposed Filter } \\
\text { Output }\end{array}$ \\
\hline lena & 22384 & 22267 & $\mathbf{2 2 3 8 3}$ \\
\hline bamboo & 32688 & 32563 & $\mathbf{3 2 6 6 3}$ \\
\hline track & 34686 & 34468 & $\mathbf{3 4 5 7 6}$ \\
\hline grass & 27381 & 27224 & $\mathbf{2 7 2 4 4}$ \\
\hline road & 39945 & 39668 & $\mathbf{3 9 8 3 0}$ \\
\hline forest & 32062 & 31650 & $\mathbf{3 1 7 5 4}$ \\
\hline wires & 41625 & 41337 & $\mathbf{4 1 4 2 5}$ \\
\hline s1 & 33467 & 33522 & $\mathbf{3 3 3 3 9}$ \\
\hline s2 & 29437 & 29370 & $\mathbf{2 9 4 1 5}$ \\
\hline s3 & 26717 & 26577 & $\mathbf{2 6 6 9 5}$ \\
\hline
\end{tabular}

From the Table 5 we observed that the proposed method is better than the median filter due to better PSNR. From the Table 6 we conclude that more edges [9] be preserved for the proposed method than median filter. 
Signal \& Image Processing : An International Journal (SIPIJ) Vol.2, No.3, September 2011

\section{CONCLUTION}

In this paper, we propose a new filtering approach for noise removal. It based on soft computing techniques which can remove the noise and at the same time tiny edges can be preserved. This enhances the reliability for getting the output image, which is more or less same with original image. From the Table 5 we conclude that the best PSNR can be achieved by using the proposed method. The proposed method is tested more than 1000 pictures, which gives the better result for each test image.

\section{REFERENCE}

[1] Abreu E., Lightstone M., Mitra S. K., Arakawa K., "A new efficient approach for the removal of impulse noise from highly corrupted images," IEEE Trans Image Processing, vol. 5, no. 6, pp. 1012-1025, 1996

[2] Abreu E., Mitra S.K., “A signal-dependent rank ordered mean (SD-ROM) filter. A new approach for removal of impulse From highly corrupted images", Proceedings of IEEE ICASSP-95, Detroit, MI, 1995, pp. 2371-2374.

[3] Arakawa K., "Median filters based on fuzzy rules and its application to image restoration", Fuzzy Sets and Systems 77 (1996) 3-13.

[4] Baudes, A., B. Coll, Morel J, M, 2005. “A non-local algorithm for noise denoising”, Computer Vision and Pattern Recognition, CVPR. IEEE Conf., 2: 60-65, 20-25

[5] Bezdek J. C., Pattern Recognition with Fuzzy Objective Function Algorithms. New York: Plenum, 1981

[6] Chen T.,. Wu H. R., “Adaptive impulse detection using center- weighted median filters," IEEE Signal Processing Letters, vol. 8, no. 1, pp. 1-3, 2001.

[7] Chen T,. Ma K. K ,. Chen L.-H, "Tri-state median filter for image denoising”, IEEE Trans. Image Processing, vol. 8, no. 12, pp. $1834-1838,1999$.

[8] Chen. T., Wu H. R., "Space variant median filters for the restoration of impulse noise corrupted images," IEEE Trans. on Circuits and Systems II: Analog and Digital Signal processing, vol. 48, no. 8, pp. 784-789, 2001.

[9] Gonzalez. R. C, Digital Image processing. $2^{\text {nd }}$ Edition TMH

[10] Hamza A., Krim H., "Image denoising A non linear robust statistical approach.” IEEE. Trans. Signal Processing 49(2), pp. 3045-3054; 2001

[11] Hwang H., Haddad R. A., “Adaptive Median filters: New algorithms and results". IEEE transaction on Image processing, 4, pp. 499-502 1995

[12] Jayaraman S., Esakkirajan, S., Veerakumar T, "Digital Image processing", Tata McGraw Hill Education Private Limited.

[13] Jeong B. , Lee Y. H., "Design of weighted order statistic filters using the perceptron algorithm," IEEE Trans. Signal Processing, vol. 42, no. 11, pp. 3264-3269, 1994.

[14] Konar A, Computational Intelligence, Springer, New York, 2004 
Signal \& Image Processing : An International Journal (SIPIJ) Vol.2, No.3, September 2011

[15] Lakshimiprabha S., A new method of image denoising based on fuzzy logic. International Journal of Soft computing 3(1): 74-77, 2008

[16] Lee Y. H., Ko, . S.-J "Center weighted median filters and their applications to image enhancement," IEEE Trans. Circuits and Systems, vol. 38, no. 9, pp. 984-993, 1991.

[17] Lee, C. S. V H Kuo, P. T Yu. "Weighted Fuzzy mean filters for Image processing”. Fuzzy Sets Sys. $89,157-180 ; 1997$

[18] Lin T.-C., Yu P.-T., Partition fuzzy median filter based on fuzzy rules for image restoration, Fuzzy Sets and Systems 147 (2004) 75 - 97.

[19] Lin T.C., Yu P.-T, “ A new adaptive center weighted median filter for suppressing impulsive noise in images”, Information Sciences 177 (2007) 1073-1087.

[20] Ross. T. J, Fuzzy logic with Engineering Applications, 2nd edition, University of New Mexico, USA, Wiley India.

[21] Sadoghi H., Yazdi, Homayouni F., "Impulsive Noise Suppression of Images Using Adaptive Median Filter", International Journal of Signal Processing, Image Processing and Pattern Recognition Vol. 3, No. 3, September, 2010

[22] Sau K., Chanda A.,"Image De-Noising with A Fuzzy Filtering Technique”, India, 2011

[23] Sau K., Chanda A., Karmakar P, "Image De-noising with Edge Preservation Using Soft Computing Techniques" Annual International Conference on Emerging Research Areas(AICERA). 2011 in Collaboration with IUPUI United States

[24] Sonka, M., Hlavac V., Boyle R.,Image Processing, Analysis, and Machine Vision, PWS Publishing, Pacific Grove, Calif, USA, 1999.

[25] Sun T. , Neuvo Y, "Detail-preserving median based filters in image processing," Pattern Recognition Letters, vol. 15, no. 4, pp. 341-347, 1994.

[26] Somasundram K. Shanmugavadivy P. Adaptive iterative order Statistics Filter, ICGST-GVIP journal Vol. 9 issue 4, pp 23-32, 2009

[27] Smolka B., Chydzinski A., Fast detection and impulsive noise removal in color images, Real-Time Imaging 11 (2005) 389 - 402.

[28] Umbaugh, S. E. Computer Vision and Image Processing, Prentice-Hall, Englewood Cliffs, NJ, USA, 1998.

[29] Wangand Z., Zhang D., "Progressive switching median filter for the removal of impulse noise from highly corrupted images,"IEEE Trans. on Circuits and Systems II: Analog and Digital Signal Processing, vol. 46, no. 1, pp. 78-80, 1999.

[30] Yli-Harja O., Astola J., and Neuvo Y., "Analysis of the properties of median and weighted median filters using threshold logic and stack filter representation," IEEE Trans Signal Processing, vol. 39, no. 2, pp. 395-410, 1991.

[31] Zhang S.,. Karim M. A, “A new impulse detector for switching median filters," IEEE Signal Processing Letters, vol. 9, no. 11, pp. 360-363, 2002

[32] Zimmermann H. J "Fuzzy set theory- And its applications", second edition, Allied publishers limited. 
Signal \& Image Processing : An International Journal (SIPIJ) Vol.2, No.3, September 2011

\section{AUTHORS}

\section{[1] Kartik Sau}

Kartik Sau completed his B.Sc. in mathematics from R. K Mission Vidyamandira, University of Calcutta. And M. Sc. in the same subject from Indian Institute of Technology, M. Tech in Computer Science from Indian School of Mines, Dhanbad. Currently he is the Head of the department of Computer Science \& Engineering in Budge Budge Institute of Technology and a member of the governing body of the same institution. He has presented many papers in International and National journals and Conferences. His area of interest includes Digital Image processing, Artificial Intelligence, Pattern Recognition, Soft computing, etc. He has more than eight years of teaching and research experience in his area of interest.

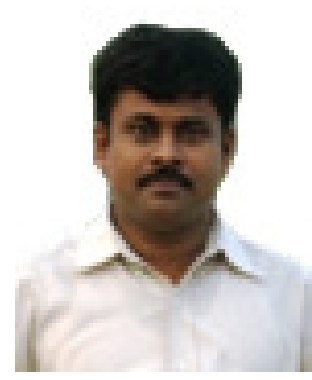

\section{[2] Dr. Amitabha Chanda}

Dr. Amitabha Chanda: visiting Professor; Department of Computer Science, UCSTA; Calcutta University. He completed his B.E in Chemical Engineering (Jadavpur), M.A. in Pure Mathematics and Ph.D in Mathematics from university of Calcutta. He was a faculty member of Indian Statistical Institute (ISI), Kolkata. Now he is also guest faculty member of ISI, Kolkata; Department of Computer Science, Rajabazar Science College, Kolkata. His area of interest includes Digital Image processing, Pattern Recognition Fuzzy logic, Genetic Algorithms, Computer Graphics, Control system Turbulence, Fractal, multifractals, Clifford Algebra, Nonlinear dynamics. He has more than fifty years teaching and research experience in his area of interest. He has presented more than 50 papers in International and National journals and Conference. Dr. Chanda is an Associate member of American Mathematical Society.

\section{[3] Pabitra Karmakar}

Pabitra Karmakar received his $M$. Tech degree in Computer Science \& Engineering from Institute of Engineering \& Management, Salt Lake Kolkata, India. He completed his B. Tech degree in Computer Science \& Engineering from Dumkal Institute of Engineering \& Technology, WBUT, India. Also he was a faculty member of Institute of Engineering and Management in Department of Computer Science.\& Engineering. He have certified in SCJP 1.4 from Sun Microsystem, USA and MTA certified form Microsoft Corporation. Also he is an IBM certified $\mathrm{C}$ and $\mathrm{C}++$ programmer. Beside this, He has a industry experience in software development. Currently he is an IT professional. His area of interest includes Digital Image processing, Pattern Recognition, Fuzzy logic, Genetic Algorithms, Neural Networks, RDBMS and programming languages.

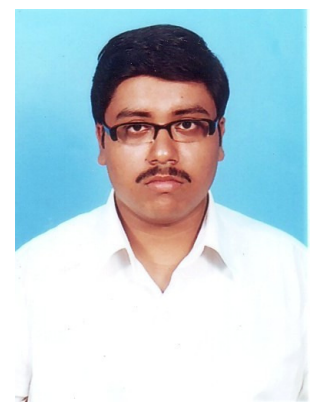

